\title{
Políticas de RH: Instrumentos de Consenso e Ambigüidade
}

\section{Rh Policies: Instruments of Consensus and Ambiguities}

\author{
Alfredo Rodrigues Leite da Silva* \\ Doutor em Administração pela UFMG. \\ Professor da FUCAPE Business School, Vitória/ES, Brasil.
}

Gelson Silva Junquilho Doutor em Administração pelo CEPEAD/UFMG. Professor Adjunto e Pesquisador do PPGADM/UFES, Vitória/ES, Brasil.

Alexandre de Pádua Carrieri Professor Dr. do CAD/FACE/UFMG. Coordenador do NEOS, Belo Horizonte/MG, Brasil.

*Endereço: Rua Fernando Ferrari, 1358, Goiabeiras, Vitória/ES, 29075-010. E-mail: alfredosilva@fucape.br 


\section{Resumo}

O objetivo deste artigo é problematizar a seguinte questão: no cotidiano do trabalho, as políticas de RH podem ser vistas unicamente pela ótica da integração organizacional ou existem implicações que geram dissensos e/ou conflitos? As propostas de integração organizacional de autores como Deal e Kennedy (1982) e Schein (1985) dificultam o reconhecimento de construções heterogêneas, inerentes à gestão de pessoas. Em contraposição, autores como Reed (1989), Martin (1992) e Aktouf (1994) baseiam uma ótica em que as políticas de RH 'fragmentam' a organização. A discussão é embasada por um estudo de caso sobre as políticas de RH, em uma Regional da Empresa Brasileira de Correios e Telégrafos. A coleta de dados se baseou em documentos e entrevistas semiestruturadas, com 26 atores em diversos níveis gerenciais. Para o tratamento dos dados utilizou-se a análise de conteúdo (Bardin, 1977). Buscaram-se padrões ou recorrências de palavras, frases, idéias e tópicos de interesse (Bogdan \& Biklen, 1994). Como conclusão, evidenciou-se que as políticas de $\mathrm{RH}$ devem ser recontextualizadas com base no reconhecimento de que remetem à integração e à fragmentação organizacional, inseridas em processo de mediação das diferenças (re)construídas socialmente.

Palavras-chave: políticas de RH; integração; cultura corporativa; práticas sociais.

\section{Abstract}

This paper proposes to discuss: at work place, could be Human Resources (HR) policies be thought by integrated organizational view or something can make dissent on it? The integration proposal from authors like Deal and Kennedy (1982) and Schein (1985), difficulty the knowledge of heterogenic constructions, existent at HR. Otherwise, authors like Reed (1989), Martin (1992) and Aktouf (1994) think HR policies as a fragmentation maker of organization. That discussion was supported by the study of HR policies at a Regional from a Brazilian Mail Enterprise. The basis to research was collected from documents and semi-structured interviews with 26 actors in some management levels. The content analysis was applied (Bardin, 1977). Repetitions of words, sentences, ideas and interest topics was looked for (Bogdan \& Biklen, 1994). As conclusion, the study shows that HR policies should be recontextualized in terms of the recognition that they are linked to integration and to organizational fragmentation, inserted in a mediation process of differences socially constructed.

Key words: HR policies; integration; corporate culture; social practices. 


\section{INTRODUÇÃO}

O objetivo deste artigo é problematizar a seguinte questão: no cotidiano do trabalho, as políticas de Recursos Humanos (RH) podem ser vistas, unicamente, pela ótica da integração organizacional, ou existem implicações que geram dissensos e/ou conflitos? Para ilustrar a discussão, analisam-se, por meio de uma pesquisa de cunho qualitativo, percepções dos gestores de uma Regional da Empresa Brasileira de Correios e Telégrafos, identificada como ' $\mathrm{ZIX}$ '(1). O estudo foca as políticas de RH aplicadas na organização, com vistas ao papel da gestão de pessoas na definição de consensos e comprometimentos dos trabalhadores, em busca da melhoria de produtividade e competitividade.

Ao discutir o tema criticam-se abordagens voltadas para a integração organizacional, relacionadas com a corrente denominada 'Cultura Corporativa'. Os representantes dessa corrente, autores como Deal e Kennedy (1982), Schein (1985), Ouchi (1986), Pascale e Athos (1986), Peters e Waterman (1986) defendem a instrumentalização da construção de significados compartilhados pelos atores de uma organização. Para esses autores, sua proposta seria alcançada pela atuação das políticas de RH junto aos membros organizacionais e na seleção e socialização de novos membros. Elas comporiam os instrumentos responsáveis pela viabilização da transmissão de soluções bem-sucedidas e pela construção das bases dos compartilhamentos sobre o que é certo ou errado na organização (Schein, 1985).

Outros autores, como Davel e Vergara (2001), opõem-se à idéia de instrumentalizar o indivíduo pela gestão de pessoas. Tais autores reconhecem a complexidade das dimensões subjetivas envolvidas nas relações humanas em organizações e vêem nelas a possível composição de um diferencial. Por essa razão, as práticas de gestão de pessoas não deveriam buscar a eliminação, mas a mediação de contradições e paradoxos das relações de trabalho. Isso faz com que se reconheça o papel de reconstrutor social do ator organizacional.

A heterogeneidade do contexto organizacional é encarada como necessidade a ser trabalhada e aproveitada, não como problema a ser resolvido. Há necessidade de mediar as diferenças. Para isso é importante que a alta administração e os demais níveis gerenciais se preparem para lidar com a autonomia e as complexidades do ator social, sem a pretensão de eliminá-las (Chanlat, 1999). Considera-se que a ausência dessa proposição pode levar à implementação de ações descoladas das práticas sociais na organização, com a intenção de obter uma suposta homogeneização dos atores, por meio de políticas de RH. 
Para aprofundar essa discussão o artigo foi dividido em seis tópicos: introdução; a discussão das propostas de integração organizacional; a proposição da conjugação das dimensões objetiva e subjetiva na gestão de pessoas e a contextualização da gestão como uma 'prática social'; os aspectos metodológicos do estudo de caso apresentado; a discussão do estudo de caso; e as contribuições para uma recontextualização das políticas de $\mathrm{RH}$.

\section{As Propostas de Integração Organizacional}

A perspectiva da integração organizacional, segundo Martin (1992), enquadra as propostas que buscam o consenso e a homogeneidade cultural como diferencial competitivo. Essa ênfase está relacionada com o paradigma funcionalista do consenso e da integração de um grupo social, em que Carrieri e Luz (1998) destacam preocupações ligadas à explicação da ordem.

Nessa abordagem se inserem estudos de autores, como Deal e Kennedy (1982), Schein (1985), Ouchi (1986), Pascale e Athos (1986), Peters e Waterman (1986) que tratam a cultura nas organizações como instrumento gerencial, isto é, variável controlada por práticas capazes de obter o consenso dos atores. O controle, a disseminação e a homogeneização dos valores organizacionais deveriam ser feitos por meio de ações corporativas, baseadas em diretrizes e valores definidos pela alta direção. Pesquisadores, como Peters e Waterman (1986), afirmam que a vantagem competitiva da organização está na construção de uma cultura forte, homogênea, compartilhada por todos e para isso é necessário o uso de vários instrumentais, como as políticas de $\mathrm{RH}$.

Diversos elementos, destacados por Deal e Kennedy (1982), podem ser trabalhados pelas políticas de RH para compor uma 'cultura corporativa'. Para os autores, o foco deve estar na gestão dos seguintes componentes: valores, heróis, ritos, rituais, mitos, tabus, e rede cultural. Ao serem tratados, eles promovem as mudanças culturais na organização como um todo, de forma que uma homogeneidade é substituída por outra homogeneidade. Conflitos e ambigüidades seriam apenas a prova do enfraquecimento de uma cultura, enquanto outra não se consolida para restabelecer o consenso. Os benefícios, os programas de treinamento, os processos de seleção, enfim os mais diversos procedimentos definidos nas políticas de RH devem levar em conta certas questões, como rituais e valores específicos, para envolver os funcionários e impulsioná-los para uma suposta integração organizacional.

Essa idéia de controlar a autonomia do ator-social nas organizações tem como 
contra-resposta estudos que reforçam o aspecto político e heterogêneo das construções sociais e as dificuldades de um completo controle gerencial (Aktouf, 1994; Chanlat, 1999). Isso significa um posicionamento baseado no reconhecimento da diversidade e complexidade das dimensões envolvidas nas relações humanas em organizações (Davel \& Vergara, 2001); enfim a compreensão da gestão como uma "prática social" (Reed, 1989).

\section{A Conjugação das Dimensóes Objetiva e Subjetiva na Gestão de Pessoas: a 'Prática Social' da Gestão}

O dinamismo das interações culturais e a diversidade humana, em termos de capacidades cognitivas, dificultam a transformação de um indivíduo em ser absolutamente previsível e controlável, mesmo quando compartilha determinados padrões em sua inserção na sociedade (Dupuis, 1996). Uma aparente conformação a determinadas intenções organizacionais não pode ser entendida como simples internalização de novos valores. Existem ações organizacionais, com funções simbólicas, que buscam impor os significados a serem internalizados pelos atores organizacionais, mas seus efeitos não são tão objetivos. De certo modo, as próprias pessoas na organização compartilham, desenvolvem e impulsionam partes do processo de construção do contexto social no qual atuam.

Conforme Chanlat (1996, p. 29), "a sociologia nos mostra muito bem que são indivíduos através dos seus atos que constroem a própria realidade social". Para o autor, em qualquer sistema social existe alguma autonomia relativa do ser humano que, submetido às próprias aspirações e possibilidades, possui certo grau de liberdade e sabe o quanto estará preparado para pagar pelo que pode atingir no plano social. Tal autonomia evidencia a pertinência em se considerar na gestão de pessoas a dimensão subjetiva, e não apenas a objetiva. Essa última tem predominado por meio de abordagens que priorizam conjuntos de técnicas e ferramentas, com vistas ao alcance da eficácia e produtividade organizacionais.

No entender de Chanlat (1999), o culto a essa racionalidade instrumental deu origem ao que se pode denominar de sociedade gerencial. Nela, as seguintes noções e princípios se manifestam: excelência, flexibilidade, desempenho, competências, qualidade total, reengenharia, cliente, benchmarking, downsizing, dentre outros. Idéias que englobam não só resultados econômico-financeiros, mas também, relacionamentos diversos e complexos entre pessoas. Dada a exigência do aumento da rentabilidade organizacional, passou a se defender a percepção da mão-de-obra como "fator de produção ou recurso", capaz de ser maximizado por meio de uma gestão que se apropria de alguns campos de 
conhecimento das Ciências Humanas, em particular a Sociologia e a Psicologia (Chanlat, 1999, p. 39). Tais interesses levaram a gestão de pessoas a uma visão voltada para a objetividade da instrumentalização, mesmo ao tratar de questões relativas à subjetividade humana.

Davel e Vergara (2001, p. 39), ao criticarem o excesso de objetividade no universo da gestão de pessoas, mostram o predomínio de um conjunto teóricoprático de "modelos normativos e funcionais que pressupõem a busca das 'melhores' ferramentas e técnicas". Assim, dotada desse caráter normativo, a gestão de pessoas carregaria consigo uma distância entre o prescrito, como regras, planos, estratégias, manuais, e o real ${ }^{(2)}$. Em contraposição a essa visão, os mesmos autores apontam a necessária conjugação da dimensão objetiva com uma outra, a subjetiva, isto é, a inserção de uma abordagem que privilegie a compreensão da ação humana e de seus significados mais complexos e profundos. A proposta vai ao encontro das de Chanlat $(1996,1999)$ e Dupuis (1996), os autores propõem pensar o ser humano nas organizações em sua experiência vivida, caracterizada por saberes e práticas cotidianas, inserido em contextos histórico-sociais específicos.

A partir dessas contribuições, defende-se uma abordagem em que o campo da gestão de pessoas não deveria ater-se à dimensão objetiva das práticas organizacionais, ou tampouco a rejeitá-la. É necessário tratar dela em conjunto com a dimensão subjetiva, como dois pólos diferenciados, mas complementares e indissociáveis. Esse é um desafio para as reflexões sobre o conhecimento científico da gestão de pessoas. Ele exige o reconhecimento de que as diversas técnicas e ferramentas administrativas, mesmo concebidas "à priori", são produzidas e reproduzidas nas organizações pela ação humana, capaz de construir e reconstruir significados e interpretações (Giddens, 1984).

A gestão de pessoas sofre as consequiências, como apregoa Chanlat (1996), da impossibilidade de eliminar toda a autonomia do ser humano e a sua capacidade de construir a própria realidade social. Ao usufruírem dessa autonomia, os atores sociais respondem à gestão de pessoas e a tudo o que a envolve, como as políticas de RH, com interpretações e comportamentos distintos de algo totalmente manipulável pela organização. Para lidar com a complexidade dessas respostas, é necessário valorizar aspectos subjetivos do ser humano e reconhecer a capacidade de expressão dos indivíduos.

Ao oferecer espaço para a subjetividade, de acordo com Zarifian (2001), a gestão de pessoas dá condições para que os atores façam frente ao imprevisto e às suas transformações. Para o autor, os gestores e demais membros organizacionais são mediadores de eventos que envolvem seus próprios pensamentos, intercâmbios, ações, apropriações e compartilhamentos de 
significações; portanto são atores com certa autonomia. É em virtude dela que as políticas de RH, além das dimensões objetivas dos interesses organizacionais, devem agregar e configurar um processo dinâmico de construção e reconstrução de saberes e práticas sociais (Reed, 1989). Esse processo é inerente ao cotidiano do trabalho. Ao ser reconhecido, ele justifica a necessidade de tratar os membros organizacionais como atores sociais, com espaços de expressão, e o processo gerencial como imerso em práticas sociais desses atores.

A base do argumento aqui desenvolvido é a relação entre a gestão e a 'prática social'. No sentido de esclarecê-lo destacam-se cinco fatores distintos e interrelacionados, a serem observados para se compreender práticas sociais de gestão, como as políticas de RH:

1 - a classe de ações nas quais os praticantes estão engajados como membros de uma comunidade ou prática;

2 - os conceitos através dos quais certos objetivos ou problemas compartilhados são identificados de um modo significativo pelos praticantes como base para o engajamento em interações recíprocas;

3 - os objetivos ou problemas através dos quais a prática é tomada e como é comunicada através do vocabulário conceitual dos seus praticantes;

4 - os meios ou recursos (materiais ou simbólicos) através dos quais o alcance de projetos importantes é buscado;

5 - as condições situacionais ou limitadoras sob as quais atividades recíprocas, os recursos que elas requerem e as relações que elas engendram entre os seus praticantes são configurados e conduzidos (Reed, 1989, p. 22).

Os cinco fatores estão associados à noção de gestão como 'prática social' de Reed (1995, p. 79): “uma configuração frouxamente integrada de práticas sociais dirigidas à junção de e controle sobre diversos recursos e atividades requeridos à produção". Esse entendimento permite pensar a organização como um conjunto de práticas. Por meio delas os indivíduos estão rotineiramente engajados na manutenção ou reestruturação dos sistemas de relações sociais, que os envolvem coletivamente (Reed, 1985). Tais práticas, como defende Giddens (1979, 1984), originam-se na vida social, que envolve procedimentos, métodos e técnicas apropriados pelas pessoas, com base em conhecimento compartilhado pelos atores sociais cognoscitivos, sobre como se comportar em determinadas situações cotidianas.

Para o autor, apesar de os sistemas sociais não serem estruturas, pois são produzidos e reproduzidos pelos atores em suas interações, eles possuem 
propriedades estruturais específicas, já que esses mesmos atores se baseiam em recursos e regras oriundos de uma variedade de contextos de atuação. A estrutura, por ser virtual, ou seja, não existir concretamente, torna-se uma propriedade abstrata dos sistemas sociais que Giddens (1984, p. 377) define como sendo "a padronização de relações sociais ao longo do tempo-espaço, entendidas como práticas reproduzidas".

Como a organização é o espaço dessas práticas, permeado por aquelas interações dos atores e sistemas sociais, neste estudo propõe-se que as políticas de RH não podem ser tratadas apenas como um instrumento objetivo dos gestores, para a integração organizacional. É necessário reconhecer implicações que geram dissensos e/ou conflitos no cotidiano organizacional, não como disfunção, mas como oportunidades de mediação de respostas inerentes ao espaço de expressão dos atores sociais, isto é, uma abordagem que pode contribuir para o estabelecimento de políticas em maior consonância com os significados construídos pelos atores. Tal proposição, além de se basear na discussão teórica realizada, também se apóia em estudo de caso realizado na 'ZIX'. Este estudo se volta para as percepções das políticas de RH da empresa, o que permitiu a observação de uma série de implicações dessas políticas no cotidiano organizacional, discutidas a seguir.

\section{Aspectos Metodológicos da Pesquisa}

Para a coleta e a análise dos dados adotou-se a abordagem qualitativa. A justificativa para a escolha é o foco em níveis mais profundos da realidade: opção necessária, segundo Minayo (2001), quando não se quer medir, mas explorar e revelar fenômenos relacionados com valores, atitudes, crenças, significados e motivações. Elementos envolvidos na tentativa de integrar a organização pelas políticas de RH, foco desta investigação.

Por dar suporte à natureza qualitativa do estudo, de forma detalhada e aprofundada, a delimitação proposta levou ao desenvolvimento de um estudo de caso (Yin, 2001), com múltiplas fontes de evidências para ampliar a abrangência da pesquisa (Triviños, 1987).

A partir do levantamento bibliográfico, foram feitos os primeiros contatos com a empresa. Em seguida foram coletados dados e solicitados documentos, o que permitiu definir os critérios para as seguintes delimitações. a) Das unidades a serem investigadas: maior volume de operação, receita e número de funcionários, todas localizadas na região 'VILAZIX'(3). b) Do período a ser investigado: gestão 
de uma diretoria voltada para a criação de 'cultura corporativa' - de 1988 a 2001. c) Dos sujeitos da pesquisa: maior tempo de exercício de função gerencial na 'ZIX', no período de 1988 a 2001, com um limite mínimo de três anos.

A decisão de focar a investigação no grupo gerencial se deve ao fato de a responsabilidade pela disseminação da 'cultura corporativa' ter sido atribuída a esse grupo pela alta administração da 'ZIX' . Assim, os gestores foram tratados como um grupo único, sem diferenciação hierárquica. Optou-se por não classificar as percepções de acordo com cada categoria, bem como se optou por 'perder' as questões referentes aos demais funcionários. Ambas as opções se justificam pelo fato de a problematização em estudo não exigir o mapeamento de toda a diversidade organizacional. É necessário focar os atores sociais envolvidos diretamente com a utilização das políticas de RH para instrumentalizar uma 'cultura corporativa', no caso aqueles inseridos no papel de gestores.

Com base nesse foco e nos critérios de seleção, formou-se um grupo com 92 atores. Ao concordar com Poirier, Clapier-Valladon e Raubaut (1983), segundo o qual de 20 a 30 sujeitos já podem permitir a saturação de informações em investigações semelhantes a esta, o número foi reduzido posteriormente para 26 atores. Assim, o grupo inicial de sujeitos foi composto da seguinte forma: o diretor regional $^{(4)}$; os três assessores da diretoria regional; os dois coordenadores ligados à diretoria; os oito ocupantes dos cargos de gerente; os três chefes de seção e dois supervisores da gerência de 'Recursos Humanos', de um total de quatro supervisores; dois de um total de 21 chefes de seção; um de um total de 11 chefes de Centros de Distribuição; dois de um total de 20 chefes de agência; dois de um total de 15 supervisores. Como a saturação de informações foi alcançada com esse grupo inicial, não foram incluídos outros sujeitos.

Essa definição baseou as entrevistas semi-estruturadas, iniciadas em conjunto com a análise de documentos. As informações foram analisadas por meio da organização sistemática dos dados em unidades manipuláveis, neste caso por 'temas'. Segundo Bardin (1977), a parte de um texto expressa determinados significados, em recortes baseados no referencial teórico que permitem estudar opiniões, atitudes, valores, crenças e tendências.

Os 'temas' foram classificados em 15 categorias: percepções dos construtores sobre a obra; o diretor e a reprodução de seus valores; construtores da cultura; monitoramento, avaliação e controle; integração; valorização; formação dos atores; valores na organização; intenções organizacionais; comunicação; contradições e paradoxos das relações de trabalho; descontentamentos dos atores; relação com o sindicato; significados das políticas de "RH"; papel das lideranças. Definidas, a partir das entrevistas, pela observação de padrões ou recorrências em palavras, frases, idéias e tópicos de interesse (Bogdan \& Biklen, 1994). Essa classificação facilitou a 
análise das questões destacadas pelos sujeitos (Bardin, 1977), o que permitiu a definição dos 'temas' a serem citados na discussão dos resultados do estudo de caso, pelo critério da maior capacidade de representar o conjunto dos dados analisados.

\section{O CASO DA 'ZIX'}

\section{Breve Histórico da Organização}

A história da 'ZIX'(5) começa em $1^{\circ}$ de janeiro de 1779 , quando os serviços postais em sua região de atuação têm início. A partir daí, os serviços postais avançaram envoltos em influências de diferentes momentos históricos, como a ascensão de D. Pedro II, a proclamação da República e a Revolução de 30. Esse último evento marca, em 1931, a criação do Departamento de Correios e Telégrafos e o surgimento da 'ZIX' como uma das Diretorias Regionais. Em 1969, durante o regime militar, ocorre a criação da Empresa Brasileira de Correios e Telégrafos (ECT). Inicia-se nova fase da Regional, agora como unidade de uma empresa. Nessa fase, em conjunto com a profissionalização dos quadros, vários cargos foram ocupados por militares até o final da década de 80. Para diversos funcionários, essa é a origem de algumas características da organização presentes até a atualidade.

Com a posse de nova diretoria, em 1988, surgiram outras influências que tiveram sua origem nas mudanças implementadas. Logo no início, o diretor apresenta sua linha de trabalho que pode ser ilustrada pelo slogan que adotou na época: 'equipe, trabalho e lealdade'. E, a partir de 1991, desenvolvem-se as primeiras ações voltadas para a gestão pela qualidade na 'ZIX'. Esse diretor veio a se afastar em 2001, fechando um ciclo. Do slogan 'equipe, trabalho e lealdade', que foi sua marca inicial, até os três pilares que, em 2001, baseavam o plano de trabalho da 'ZIX': 'lucratividade, qualidade e harmonia'. Um período que, segundo o próprio ex-diretor e diversos gerentes, foi marcado pela intenção, até certo ponto bemsucedida, de preparar os funcionários em cargos gerenciais para assumirem novo papel na gestão de pessoas na organização: envolver os funcionários e direcionálos para construírem compartilhamentos mais adequados aos interesses de 'todos'.

\section{Dissensos e Consensos nas Políticas de RH}

A partir de 1988, as políticas de RH na 'ZIX' receberam mais atenção da alta direção, quando assumiu um diretor que enfatizava a importância do elemento humano. Segundo ele: 
“[...] 70\% do tempo gasto numa organização, eu afirmo isso, categoricamente, $70 \%$ é com conflitos com pessoas, porque você não trabalha essa droga de $70 \%$ como ênfase, o resto é o resto, o resto você investe em tecnologia [...]" (DIRETOR 1).

Essa preocupação impulsionou a composição de três comitês: qualidade, lucratividade e harmonia, que constituiriam os três pilares de sustentação da organização. Cada um deles reforçaria as intenções organizacionais nas respectivas áreas da empresa. O primeiro deles, o da qualidade, surgiu em 1994; o segundo, o da lucratividade, em 1996; e por fim, em 1999, surgiu o da harmonia. Esse último, com o objetivo de dar suporte aos dois anteriores, tratava das pessoas. Ele agregava ações já implementadas voltadas à qualidade de vida no trabalho, às relações humanas em geral, aos funcionários e seus familiares.

As ações voltadas para as pessoas na organização não eram novidade. Em nível nacional, já se implementavam propostas voltadas para a melhoria da qualidade de vida no trabalho dos funcionários, a partir de diretrizes corporativas da Direção Central, de Brasília. A inovação do comitê harmonia era aliar essas ações com outras, locais, desenvolvidas a partir de necessidades específicas, dos funcionários ou da alta direção, no sentido de viabilizar interesses organizacionais. A proposta consistia no envolvimento dos funcionários por meio de ações que possibilitassem a sua integração no contexto organizacional. Nesse processo os atores envolvidos destacaram nove influências: a) um indivíduo, o diretor; b) o papel dos gestores; c) a área de planejamento; d) a área de RH; e) a área de comunicação; f) os Treinamentos no Local de Trabalho (TLT); g) as reuniões; h) os boletins internos; i) e o instrumento de avaliação denominado Gerenciamento de Competências e Resultados (GCR).

Esses destaques revelaram o alinhamento da 'ZIX' com as propostas de autores da abordagem 'integrativa de cultura', como Peters e Waterman (1986), sobre a construção da integração organizacional por meio de intervenções dos gestores. Uma 'cultura corporativa' foi então planejada e disseminada por toda a organização. $\mathrm{Na}$ 'ZIX' esses dois processos se concentravam nas áreas de planejamento, $\mathrm{RH}$ e comunicação, como revelado pelos respondentes. Eles também enfatizaram algumas ações desenvolvidas pelas áreas, tais como estas: treinamentos, boletins e avaliações.

A constatação do alinhamento da 'ZIX' com a abordagem 'integrativa' de cultura foi reforçada, quando o diretor destacou que exigia dos gerentes a adoção, junto aos subordinados, de uma postura igual a que ele os submetia. Segundo a maioria dos entrevistados, essa preocupação norteou o início do processo implementado pelo diretor, no sentido de envolver todos os atores em nova proposta de gerenciamento, que se baseou na ênfase do papel das pessoas e na construção de uma integração organizacional. Conforme um assessor: 
“[...] a partir de 88, ele [o diretor] valorizou muito a parte de 'Recursos Humanos', criou vários programas voltados para 'Recursos Humanos', foi uma valorização das pessoas que ele tentou implantar. Ele gostava de fazer pesquisa e perguntar para as pessoas se estavam satisfeitas, como que estava o trabalho" (ASSESSOR 2).

Nesse sentido, em consonância com as proposições de Schein (1985), a gestão de pessoas foi o caminho adotado para a implementação de mudanças voltadas para a integração e capazes de resolver diversos problemas organizacionais. A atuação da alta administração surge associada ao gerenciamento de elementos da 'cultura corporativa', assinalados por Deal e Kennedy (1982), tais como: valores, heróis e rituais, o que é ilustrado pela visão que se tinha do diretor, como um herói a ser seguido por valorizar as pessoas e promover o desenvolvimento da organização. Essa imagem foi reforçada por meio de rituais, como o café da manhã com o diretor ou os treinamentos de que ele participava ao lado dos funcionários, com conteúdos que disseminavam os valores pregados pela alta administração.

Para a corrente da 'cultura corporativa', esses esforços comporiam um cotidiano de trabalho consensual na 'ZIX'. Entretanto dentre os próprios gestores não se observou o pleno consenso. A despeito de eles concordarem sobre o fato de o diretor se esforçar na disseminação de certos compartilhamentos, também afirmavam não acreditar em algumas propostas que tinham que repassar, como se observa no depoimento a seguir:

"[...] eu tenho um sentimento de profissional quanto ao meu papel na empresa [...] porque nem tudo o que você passa, lá no seu interior, você acredita [...]. A posição pessoal pode levar a se discordar de algumas questões, mas nunca com a equipe, apenas com o escalão superior" (CHEFE DE CDD 1).

Fica clara a percepção quanto ao comportamento esperado de um profissional na 'ZIX' : transmitir as propostas organizacionais, como se nelas acreditasse. $\mathrm{O}$ consenso deve ser externado, mesmo que não se concorde com o próprio discurso. A 'cultura corporativa', supostamente baseada em internalizações, apresenta-se como 'fachada'. A explicação para isso, segundo Davel e Vergara (2001), está nas complexidades inerentes às subjetividades humanas, que dificultam a instrumentalização do ator social.

A racionalidade instrumental falha na construção de um consenso internalizado em bases culturais. Esse argumento se legitima nos estudos sociológicos destacados por Chanlat (1996), que mostram a autonomia relativa do ser humano, possuidor de aspirações e de possibilidades, preparado para pagar pelo que quer alcançar no plano social. $\mathrm{O}$ ator pode assumir certos dilemas e reproduzir um discurso com o qual não concorda. Para isso ele não precisa internalizar valores ou assumir nova cultura, apenas analisa os prós e contras de sua atitude no plano social e, com base em certa autonomia, define sua conduta. 
Como mostra Aktouf (1994), a cultura internalizada pelos atores não é aquela instrumentalizada pelas estratégias organizacionais. Vê-se que essas estratégias são apenas mais algumas influências, dentre muitas outras interdependentes, tais como: a condição de vida, a estrutura social e a história. Para o autor, a cultura é uma construção social complexa que não pode ser controlada por atores sociais ou estratégias organizacionais.

A conduta do diretor ilustra esse entendimento. Ele próprio afirma ter alterado profundamente a maneira de ver determinadas questões após a experiência de ter executado, por duas vezes, todas as atividades de um 'carteiro' durante um dia inteiro. Como os demais atores passam cotidianamente por experiências, dentro e fora do contexto organizacional, eles também passam a ver determinadas questões de maneiras diferentes. Ao longo da vida, o conjunto dessas experiências compõe as internalizações compartilhadas socialmente com outros membros da sociedade a que pertencem. A cultura, socialmente construída nesse processo, não parece ser facilmente substituída por outra, a partir de algumas experiências limitadas ao contexto organizacional, em curto período de tempo.

Observou-se que parte das posturas do diretor se relacionam com aspectos da cultura brasileira, que extrapolam a 'ZIX', já investigados por autores como Barros e Prates (1996). Um exemplo é o papel paternalista ${ }^{(6)}$ do gestor, que permeia a sociedade brasileira em conjunto com a tecnocracia. Os gestores nacionais unem conhecimentos técnicos da administração com práticas paternalistas que avançam além da esfera organizacional, em uma relação complexa e ambígua (Barros \& Prates, 1996). Isso é ilustrado pelo fato de o diretor atender algumas demandas de funcionários, como: a necessidade de um 'bico' para complementar a renda; patrocínios para funcionários ou dependentes; ou a possibilidade de uma ascensão profissional, dentro ou fora da empresa.

As manifestações paternalistas legitimam o discurso de que o funcionário obtém vantagens ao se integrar na organização; portanto elas têm em comum com outras ações a busca pela integração organizacional. Apesar desses esforços, o sentido de integração não se apresentou como algo homogêneo e compartilhado na 'ZIX' . Várias críticas surgiram até mesmo dos níveis gerenciais mais próximos da alta direção. Nesse sentido, evidenciaram-se diferenças de opiniões sobre as ações do diretor entre os demais gestores, a despeito das práticas de gestão de pessoas às quais eram submetidos e que, por sua vez, também submetiam seus subordinados. As próprias políticas de $\mathrm{RH}$, reconhecidas como contribuintes para a gestão, foram responsabilizadas pelas pressões sobre os gestores. Elas provocaram dissensos oriundos de ações apresentadas como preponderantes no cotidiano gerencial. 


\section{Ações Preponderantes nas Práticas de Gestão de Pessoas}

Para fins de análise, com base nos dados coletados, as ações preponderantes nas práticas de gestão de pessoas na 'ZIX' podem ser divididas em quatro grupos de ações, de acordo com os seus objetivos: a) disseminação das idéias corporativas; b) monitoramento, a avaliação e controle; c) valorização dos atores; d) e formação dos atores. Esses grupos se revelam complementares e inter-relacionados de diversas maneiras, tais como: a disseminação das idéias corporativas divulga as bases do monitoramento, da avaliação, do controle, da valorização e da formação dos atores que, por sua vez, reforçam aquela disseminação; o monitoramento, a avaliação e o controle influenciam a definição de quem deve ser valorizado; a valorização legitima e impulsiona a formação dos atores. Tal imbricamento explica o fato de os quatro grupos serem colocados como preponderantes para a tentativa de construção de compartilhamentos na 'ZIX'.

O imbricamento mencionado parece remeter a um contexto consensual; mas, segundo os respondentes, nele se encerra um cotidiano permeado pela incerteza e por ambigüidades diretamente ligadas às próprias ações da gestão de pessoas. Davel e Vergara (2001, p. 39) esclarecem que tais contradições se evidenciam "nas práticas cotidianas que demandam das pessoas, simultaneamente, atitudes individualistas, empregabilidade, flexibilidade, adaptabilidade e, também, atitudes coletivistas para trabalhar em equipe, comprometimento, adesão a uma cultura forte, qualidade".

O conjunto das demandas e pressões envolve os grupos de ações e evidenciam uma inserção tanto na dimensão formal, destacada no Quadro 1, baseado nas diretrizes organizacionais, quanto na dimensão informal, apresentada no Quadro 2 com ênfase nas práticas sociais (Reed, 1985, 1989, 1995).

\section{Quadro 1: Ações Formais Relacionadas com as Políticas de RH Baseadas nas Diretrizes Organizacionais}

\begin{tabular}{|c|c|c|c|}
\hline $\begin{array}{l}\text { Disseminação das } \\
\text { idéias corporativas }\end{array}$ & $\begin{array}{l}\text { Monitoramento, } \\
\text { avaliação e controle }\end{array}$ & Valorização dos atores & Formação dos atores \\
\hline $\begin{array}{l}\text { Controle sobre o } \\
\text { número de Reuniões, } \\
\text { com metas a serem } \\
\text { atingidas }\end{array}$ & $\begin{array}{l}\text { Gerenciamento de } \\
\text { Competência e } \\
\text { Resultados (GCR): } \\
\text { avalia metas de }\end{array}$ & $\begin{array}{l}\text { Benefícios genéricos: assistência } \\
\text { médica, salário em dia, suposta } \\
\text { estabilidade e segurança }\end{array}$ & $\begin{array}{l}\text { Controle sobre o } \\
\text { número de treinos, com } \\
\text { metas a serem atingidas }\end{array}$ \\
\hline $\begin{array}{l}\mathrm{TV}, \text { jornais, boletins } \\
\text { internos, peças de }\end{array}$ & $\begin{array}{l}\text { produtividade, } \\
\text { competências e } \\
\text { comportamento }\end{array}$ & $\begin{array}{l}\text { Premiações esporádicas, nunca } \\
\text { em dinheiro, em promoções } \\
\text { isoladas }\end{array}$ & $\begin{array}{l}\text { Treinamento no Local } \\
\text { de Trabalho (TLT) }\end{array}$ \\
\hline $\begin{array}{l}\text { teatro encomendadas } \\
\text { pela empresa, cafés da } \\
\text { manhã }\end{array}$ & $\begin{array}{l}\text { Centralizar nos } \\
\text { gerentes os pedidos de }\end{array}$ & $\begin{array}{l}\text { Gratificações incorporadas ao } \\
\text { salário }\end{array}$ & $\begin{array}{l}\text { Cursos externos de } \\
\text { interesse da organização }\end{array}$ \\
\hline $\begin{array}{l}\text { Compor equipes de } \\
\text { trabalho para tratar de } \\
\text { questões específicas }\end{array}$ & $\begin{array}{l}\text { informações / } \\
\text { reclamações referentes } \\
\text { aos funcionários }\end{array}$ & $\begin{array}{l}\text { Mudança de função, inclusive } \\
\text { para níveis de chefia, limitados } \\
\text { ao cargo do funcionário }\end{array}$ & $\begin{array}{l}\text { O Boas Vindas é o } \\
\text { primeiro treinamento } \\
\text { dos recém-contratados }\end{array}$ \\
\hline
\end{tabular}

Fonte: dados da pesquisa. 


\section{Quadro 2: Ações Informais Relacionadas com as Políticas de RH e com as Práticas Sociais}

\begin{tabular}{l|l|l|l}
\hline $\begin{array}{l}\text { Disseminação das } \\
\text { idéias dos atores } \\
\text { organizacionais }\end{array}$ & $\begin{array}{l}\text { Monitoramento, } \\
\text { avaliação e controle }\end{array}$ & Valorização dos atores & Formação dos atores \\
\hline $\begin{array}{l}\text { Conversas e } \\
\text { relacionamentos } \\
\text { informais durante o } \\
\text { trabalho e nos } \\
\text { intervalos }\end{array}$ & $\begin{array}{l}\text { Avaliação pessoal, } \\
\text { com base no convívio } \\
\text { cotidiano }\end{array}$ & $\begin{array}{l}\text { Ignorar o erro de um 'bom' } \\
\text { funcionário } \\
\text { Ouvir o 'bom' funcionário e } \\
\text { oferecer vantagens, como abono } \\
\text { de faltas e folgas }\end{array}$ & $\begin{array}{l}\text { Demonstrações, no local } \\
\text { de trabalho, do 'jeito } \\
\text { certo' de se conviver e } \\
\text { trabalhar }\end{array}$ \\
\hline
\end{tabular}

Fonte: dados da pesquisa.

No Quadro 1 e no Quadro 2 observa-se que as ações relacionadas com as políticas de RH, além de se inserirem nas dimensões formal e informal, podem ser opostas, complementares ou apenas distintas. Assim, originam relações complexas, envoltas em consensos, conflitos, dilemas e ambigüidades no cotidiano organizacional. As ações para formação dos atores servem como exemplo: na dimensão formal (Quadro 1) o Boas Vindas é o primeiro treinamento dos recém-contratados, mas alguns conteúdos desse treinamento, como a forma de tratar os colegas, configuram-se de maneiras distintas nas demonstrações, no local de trabalho, do 'jeito certo' de se conviver e trabalhar, ação inserida na dimensão informal (Quadro 2). No tocante às informações sobre o papel de uma unidade da empresa, as demonstrações no local de trabalho são complementares, pois detalham no cotidiano as atribuições das unidades mencionadas no Boas Vindas. Quando surge a questão da avaliação, evidenciase a oposição, pois enquanto o Boas Vindas apresenta um sistema de avaliação neutro, no qual os melhores são beneficiados, as demonstrações no local de trabalho disseminam a idéia de que os melhores trabalham mais e são prejudicados.

O exemplo dado vai ao encontro da ambígua relação em que as influências sobre o novo funcionário envolvem simultaneamente o treinamento inicial, baseado nas intenções da organização, e os colegas no cotidiano, como destacado no Quadro 3. O referido quadro evidencia que as implicações ilustradas no exemplo anterior surgem nos quatro grupos de ações para gestão de pessoas destacadas. Ao remeterem a conflitos, dilemas e ambigüidades, tais implicações corroboram os estudos de Davel e Vergara (2001, p. 39), sobre as 'contradições inerentes às funções atuais da gestão de pessoas', e revelam um conturbado contexto organizacional.

\section{Conflitos, Dilemas e Ambigüidades Relacionadas com as Políticas de RH}

$\mathrm{Na}$ 'ZIX' os respondentes atribuíram às ações relacionadas com as políticas de 
RH uma infinidade de conflitos, dilemas e ambigüidades inerentes às diferentes percepções e intenções que envolvem questões inseridas naquelas políticas. $\mathrm{O}$ Quadro 3 apresenta as questões colocadas pelos respondentes.

\section{Quadro 3: Conflitos, Dilemas e Ambigüidades Relacionadas com as Políticas de RH e as Práticas Sociais}

\begin{tabular}{|c|c|c|c|}
\hline $\begin{array}{l}\text { Disseminação das } \\
\text { idéias corporativas }\end{array}$ & $\begin{array}{c}\text { Monitoramento, a } \\
\text { avaliação e o controle }\end{array}$ & Valorização dos atores & Formação dos atores \\
\hline $\begin{array}{l}\text { A comunicação é } \\
\text { compulsória, quem } \\
\text { não a utilizar perde } \\
\text { pontos na avaliação } \\
\text { Diferentes atores } \\
\text { entendem as } \\
\text { mesmas } \\
\text { informações de } \\
\text { formas diversas } \\
\text { As reuniões são } \\
\text { importantes, mas } \\
\text { exigem condições, } \\
\text { inexistentes, para } \\
\text { que sejam } \\
\text { realizadas } \\
\text { Os atores podem } \\
\text { usar as informações } \\
\text { conforme seus } \\
\text { interesses pessoais } \\
\text { e grupais }\end{array}$ & $\begin{array}{l}\text { Muitos funcionários } \\
\text { com uma avaliação } \\
\text { excelente não recebem } \\
\text { nenhum benefício } \\
\text { financeiro } \\
\text { Há distanciamento } \\
\text { entre o cotidiano } \\
\text { organizacional e o } \\
\text { processo de definição } \\
\text { dos critérios da } \\
\text { avaliação } \\
\text { Os laços pessoais } \\
\text { construídos no } \\
\text { cotidiano e nas ações } \\
\text { organizacionais } \\
\text { interferem nas } \\
\text { avaliações } \\
\text { O absenteísmo é visto } \\
\text { como desonestidade, } \\
\text { problemas de saúde ou } \\
\text { instrumento político }\end{array}$ & $\begin{array}{l}\text { Os benefícios devem ser } \\
\text { oferecidos a todos, sem } \\
\text { discriminação e } \\
\text { distinguir o 'bom do } \\
\text { 'mau funcionário } \\
\text { O bom funcionário } \\
\text { ganha mais tarefa e o } \\
\text { ruim é premiado com o } \\
\text { descanso } \\
\text { O sofrimento é coletivo } \\
\text { e inclui os gestores, pois } \\
\text { a falta de valorização é } \\
\text { culpa de uma força } \\
\text { superior, o Governo } \\
\begin{array}{l}\text { O gestor oculta sua } \\
\text { incerteza para garantir } \\
\text { aos funcionários que a } \\
\text { empresa o valoriza } \\
\text { A carga de trabalho } \\
\text { dificulta demonstrar que } \\
\text { se quer o bem da pessoa }\end{array}\end{array}$ & $\begin{array}{l}\text { O gestor deve aprender a omitir idéias e } \\
\text { sentimentos e agir como seus superiores } \\
\text { O aperfeiçoamento contínuo é necessário } \\
\text { para garantir a empregabilidade, mas } \\
\text { todos querem a estabilidade } \\
\text { O treinamento inicial, baseado nas } \\
\text { intenções da organização, e os colegas, } \\
\text { no cotidiano, influenciam o novo } \\
\text { funcionário } \\
\text { O gestor deve ser preparado para lutar } \\
\text { contra o sindicato, que luta a favor do } \\
\text { gestor, pois é um funcionário } \\
\text { O resgate do mau funcionário é } \\
\text { necessário, mas gera impunidade } \\
\text { A empresa só quer lucro, mas, trata da } \\
\text { qualidade de vida e da empregabilidade } \\
\text { do funcionário }\end{array}$ \\
\hline
\end{tabular}

Fonte: dados da pesquisa.

No Quadro 3, observa-se que, apesar de a possibilidade das ações formais (Quadro 1) e informais (Quadro 2) relacionadas com as políticas de RH convergirem para a intenção de integrar a organização, surgem implicações capazes de afastá-las desse objetivo. $\mathrm{Na}$ 'ZIX' é evidente o interesse em modelar competências e comportamentos ligados aos valores desejados e disseminados pela alta direção, como defendido por Deal e Kennedy (1982). Mas em virtude de certa liberdade dos atores sociais nem sempre é a integração o resultado das construções sociais na organização, permeada por formas próprias dos atores de comunicação e avaliação para mediação dos seus interesses. Os estudos de Zarifian (2001, p. 151) evidenciam tal extrapolação da dimensão formal, ao mostrarem que "apesar da redução da comunicação à transmissão de ordens e diretrizes [...] uma comunicação autêntica, de natureza intersubjetiva, emerge na empresa moderna".

De acordo com os gestores, a disseminação das idéias corporativas (Quadro 
3) deveria viabilizar a integração organizacional por meio da comunicação; mas, ao ser imposta, em condições inadequadas, e por envolver interpretações e interesses diversos, transforma-se em fonte de problemas, conflitos e dissensos. Essas implicações também foram atribuídas aos instrumentos utilizados para viabilizar o monitoramento, a avaliação e o controle (Quadro 3) dos membros da 'ZIX' . A despeito do discurso da avaliação neutra, proposto pela alta direção, os gestores revelaram percepções sobre inconsistências oriundas da ausência de benefícios para os melhores funcionários, critérios incoerentes com o cotidiano do trabalho e influências pessoais interferindo na avaliação, o que afasta a organização de uma integração.

O mesmo imbricamento entre aspectos formais e informais e as evidências da subjetividade dos atores organizacionais permeiam as questões relativas à valorização dos atores (Quadro 3). Um exemplo é a busca por valorizar o 'bom' funcionário e não o 'mau'. Os gestores defenderam o argumento de que o primeiro deveria ter vantagens sobre o segundo, mas reconheceram que no cotidiano do trabalho essa 'lógica' se inverte, ou seja, o mau funcionário teria vantagens sobre o bom, como se observa no depoimento:

"Existe uma reclamação muito grande de todos os funcionários, da base, principalmente, que o bom funcionário é punido, porque, se o empregado é bom; ele acaba ganhando mais tarefa; se for ruim, deixam ele para lá" (CHEFE DE SEÇÃO 3).

Uma alternativa para fazer frente a essa questão poderia estar nas políticas de RH, isso se focassem determinadas ações para desenvolver a percepção de valorização dos supostos melhores funcionários. No entanto o papel das políticas de RH se apresentou em um contexto assistencialista. Os gestores as expuseram como algo que deveria beneficiar todos os funcionários. Eles também destacaram o problema das limitações financeiras, obstáculo às premiações, mas evidenciaram que elas não impedem o aperfeiçoamento do funcionário, nem a forma de valorizálo. Ainda assim, destacou-se que mais do que uma valorização esse é um caminho para a organização influenciar a formação dos trabalhadores, pois ela só autoriza o que está de acordo com seus objetivos.

Para justificar essas e outras deficiências na valorização dos funcionários, observouse o uso do discurso de que a responsabilidade é do Governo Federal e o sofrimento é coletivo. Ele incluiria os gestores e a própria 'ZIX' que, portanto, não deveria ser responsabilizada ou 'punida' por seus membros. Ainda no tocante à valorização, os gestores indicaram a insatisfação com a situação, mas destacaram a necessidade de ocultá-la dos demais membros. Novamente surgem pressões sobre os gestores para que externem, com convicção, uma realidade em que nem sempre acreditam, mas que supostamente viabilizaria a disseminação do sentimento de valorização do funcionário. Isso é ilustrado pelo fragmento a seguir: 
“[...] eu tenho que estar no dia-a-dia tranqüilizando o funcionário de que a empresa está fazendo de tudo para valorizá-lo cada vez mais. E aí você tem que estar trabalhando as suas incertezas, porque a gente não sabe o que vem. Eu cheguei a passar por situações de entrar em choque, chegar em casa e pensar: e aí? O que eu vou ser dentro da empresa? E no outro dia eu tinha que estar falando: 'Vocês têm que confiar na empresa"'(COORDENADOR 1).

De forma recorrente, os gestores afirmaram omitir idéias e sentimentos, sob a justificativa de que era para o bem do processo de gestão de pessoas. A omissão se caracteriza como resposta dos gestores em face das tensões cotidianas. Eles sofrem as consequiências por atuarem, simultaneamente, de maneira individualista e coletivista (Davel \& Vergara, 2001), em contexto cultural heterogêneo (Aktouf, 1994). Isso foi evidenciado por funcionários em diferentes níveis gerenciais e em questões diversas, o que leva a se questionar como eles eram preparados para lidar com essas pressões, ou seja, a sua formação.

A formação dos atores (Quadro 3) na 'ZIX' envolve treinamentos ou cursos mais prolongados a que o indivíduo se submete ao ingressar na organização ou ao se preparar para assumir funções de chefia. Assim os gestores seriam preparados para lidar com as pressões organizacionais. No processo destacam-se as dificuldades em se lidar com um grupo heterogêneo, com origens e histórias de vida diferentes, sendo preparados para ocupar posições gerenciais na 'ZIX' e seguir linhas de ações semelhantes, definidas pela alta direção.

A diversidade amplia o desafio da organização, ao pretender a preparação dos funcionários para assumirem as funções de chefia em determinada linha de trabalho, de forma integrada e consensual. A tentativa de construir uma 'cultura corporativa' esbarra, já no nível gerencial, no processo, destacado por Aktouf (1994, p. 50), de composição de culturas opostas ou distintas em uma mesma comunidade, a partir das "experiências subjetivas das pessoas" em suas interrelações histórico-sociais.

A busca por fazer frente a esse desafio parece concretizar-se no discurso de que há necessidade de as pessoas se aperfeiçoarem constantemente, para garantir seu espaço no mercado de trabalho. O discurso envolve os próprios gestores, que também o disseminam, e seus subordinados. Legitimou-se, assim, a necessidade do desenvolvimento contínuo dos funcionários e a proposta dos treinamentos constantes. Essa necessidade passa a ser vista como alternativa lógica para se obter o 'melhor' profissional para a 'ZIX' que, por questões de comprometimento e sobrevivência, buscaria o desenvolvimento.

Alguns entrevistados destacaram, ainda, a necessidade de se tratar da empregabilidade, pois qualquer um poderia se ver na situação da procura de 
emprego, mesmo eles, o que legitima a importância de se aperfeiçoar. Mas fatores como a segurança e a estabilidade do emprego, valorizados por todos segundo os respondentes, são incompatíveis com a idéia de empregabilidade. Ela sempre surge vinculada à necessidade de se preparar para uma possível saída da empresa, e não para se manter nela. Vê-se a ambigüidade do discurso que tenta conciliar os temas da estabilidade e da empregabilidade na 'ZIX'. Da mesma maneira, o discurso de que a empresa visa ao lucro, confunde-se com o de que a empresa visa à qualidade de vida do funcionário. O primeiro discurso parece ser legitimado pelo segundo, o que se revela pela apropriação do discurso da qualidade de vida, mas permeado pelo reconhecimento de que a prioridade dos interesses corporativos é o lucro.

A questão da prioridade no lucro é consenso; entretanto está sempre associada a outras questões que a legitimam, tais como: a ampliação da empregabilidade do funcionário, o aumento de sua qualidade de vida, a preocupação com o seu crescimento profissional, a 'recuperação' do mau funcionário. Esses são argumentos utilizados pelos gestores para justificar ações a serem tomadas e às quais tanto os funcionários, quanto eles próprios, terão que se submeter. Tais argumentos são (re)produzidos pelos próprios atores organizacionais que ao (re)construir seus significados e interpretações, os legitimam (Giddens, 1984).

O processo de (re)construção mencionado pode, por exemplo, remeter um grupo ao entendimento de que o comprometimento é algo benéfico para todos. Esse é o discurso defendido pelo diretor, mas ele próprio reconhece ser o comprometimento uma possível fonte de sofrimento, quando ocorrem mudanças organizacionais. Vários gestores compartilham do discurso do diretor e, assim como ele, (re)constroem o significado do comprometimento como algo capaz de ser não apenas benéfico a todos, mas também maléfico, o que vai depender das mudanças e da gestão de pessoas na organização. Isso ilustra as ambigüidades presentes nas manifestações dos gestores sobre seu papel na implementação de políticas de RH. Eles apresentaram práticas e discursos diversos, nem sempre opostos, acompanhando interesses, objetivos, valores, interpretações, intenções; enfim, uma diversidade de questões referentes às organizações, aos indivíduos e aos grupos envolvidos.

A 'ZIX' revela em seus gestores o impacto dos imbricamentos das dimensões identificadas por Reed (1989) como técnicas, políticas e críticas. Ao buscarem implementar as políticas de RH como instrumentos de consenso, os gestores interagem na 'prática social', com base na estrutura formal, nos aspectos políticos do nível microssocial das organizações, e nas influências institucionais referentes a conflitos de poder e interesses que extrapolam o nível organizacional (Reed, 1989). No processo, aquele consenso intencionado passa a ser permeado pela ambigüidade, também disseminada pelas políticas de RH. 
Remetendo-se ao problema de pesquisa proposto, pode-se afirmar que as implicações das políticas de RH vão além do plano da integração organizacional. Elas engendram dissensos e/ou conflitos no cotidiano organizacional, advindos da (re)interpretação das mesmas políticas na 'ZIX', por parte dos atores responsáveis por sua própria implementação. Ou seja, observou-se a conjugação da dimensão objetiva das políticas de RH, permeada pelas intenções organizacionais, à dimensão subjetiva, inerente à ação dos atores em face daquelas mesmas políticas, o que, conforme Chanlat (2001), Davel e Vergara (2001), reforça a idéia da própria gestão de pessoas como 'prática social' (Reed, 1985, 1989, 1995).

\section{Contribuições para uma Recontextualização das Políticas DE RH}

Este estudo teve, como objetivo, a problematização da inserção das políticas de RH na ótica da integração organizacional. Questionou-se a possibilidade de existirem implicações que geram dissensos e/ou conflitos no cotidiano do trabalho. Nesse sentido, o referencial teórico discutido e as evidências oriundas da investigação empírica indicaram que as políticas de RH remetem à integração e à fragmentação organizacional.

As percepções analisadas indicaram uma realidade organizacional que distancia as políticas de RH do conceito de instrumento de consenso e integração. Legitimouse a oposição às idéias dos autores da corrente da 'cultura corporativa', tais como Deal e Kennedy (1982), Schein (1985), Ouchi (1986), Pascale e Athos (1986), Peters e Waterman (1986). As ambigüidades reveladas nas práticas de gestão de pessoas na 'ZIX' inserem as implicações das políticas de RH na concepção de 'prática social' (Reed, 1985, 1989, 1995).

Deve-se destacar que, independentemente dos esforços da alta direção, o indivíduo, a partir de sua certa autonomia (Chanlat, 1996) (re)constrói significados (Giddens, 1984). Quando a 'ZIX' buscou nas políticas de RH um caminho para construir compartilhamentos consensuais, além de obter alguns consensos, como o entendimento da importância das políticas de RH para o processo gerencial, também obteve ambigüidades. Tem-se como exemplo disso a visão do comprometimento como algo 'bom para todos', mas que gera sofrimento. A despeito de se disseminar, por meio dos treinamentos e das avaliações, o valor do comprometimento como algo benéfico e necessário, muitos gestores, incluindo o próprio diretor, têm nele algo que promove sofrimento em caso de mudanças. Como a mudança na atualidade é reconhecida como inerente ao contexto organizacional, o comprometimento se transforma em 'sinônimo de sofrimento'. 
Tal ambigüidade e as outras discutidas ao longo da análise do caso da 'ZIX', bem como os dilemas e conflitos a elas relacionados têm, na idéia da gestão como 'prática social' (Reed, 1985, 1989, 1995), um caminho para sua mediação. Há, assim, a possibilidade de se lidar com a conjugação das dimensões objetiva e subjetiva inerentes ao cotidiano do trabalho (Davel \& Vergara, 2001).

As evidências do caso da 'ZIX' sustentam o argumento de que às intenções das políticas de RH, no plano objetivo, das regras formais e prescritas, agregamse os significados e conhecimentos (re)construídos pelas pessoas no plano subjetivo. Nesse processo, os obstáculos à instrumentalização da internalização ou eliminação de valores dos atores ficam evidentes. É necessário o reconhecimento, defendido por Aktouf (1994), de que o indivíduo tem existência anterior, origem, história de vida, e, como afirma Chanlat (1996), certa autonomia em suas interações cotidianas.

É o alinhamento com esses e outros autores, na crítica às propostas de integração organizacional, que marcou as contribuições deste artigo para os estudos organizacionais. Aqui se esclareceu parte das implicações das políticas de RH nas organizações e assim ocupou-se uma lacuna na literatura, pois os críticos da abordagem integrativa não enfatizam, especificamente, as implicações das políticas de RH na tentativa de se integrar a organização, por meio uma cultura única. Este e outros estudos, que criticam a abordagem da 'cultura corporativa', têm em comum a oposição à busca por construir uma cultura única, homogênea, de acordo com os interesses organizacionais. Ao explicar parte da origem da fragmentação organizacional, aqui atribuída às políticas de RH, o presente artigo complementa os demais.

A partir dessa contribuição, propõe-se que as políticas de RH sejam recontextualizadas. Ela deve admitir o espaço do ator organizacional na construção e reconstrução de práticas e significados (Giddens, 1984), advindos de suas interpretações daquelas próprias políticas. Esses espaços subjetivos, caracterizados por conflitos, dilemas e ambigüidades e conjugados com o plano da objetividade das políticas de RH não devem ser desprezados pela alta direção organizacional. Conclui-se que a gestão de pessoas envolve muito mais a mediação das diferenças, (re)construídas cotidianamente com as pessoas, do que apenas a integração organizacional.

\section{Artigo recebido em 15.10.2004. Aprovado em 09.05.2005.}




\section{NOTAS}

${ }^{1}$ O nome 'ZIX' é fictício e foi adotado para preservar a imagem da Regional, como solicitado pela organização.

${ }^{2} \mathrm{O}$ real é aqui entendido como o cotidiano, as relações sociais, as experiências vividas pelos seres humanos no interior das organizações.

${ }^{3}$ A 'VILAZIX' é um município fictício, para preservar a imagem da Regional, como solicitado pela organização.

${ }^{4}$ Diretor que atuou na 'ZIX' no período investigado, de 1988 a 2001, atualmente está na iniciativa privada.

${ }^{5}$ As informações apresentadas sobre a história da 'ZIX' foram obtidas por meio de entrevistas e documentos internos. Os dados bibliográficos referentes aos documentos não foram revelados por exigência da organização.

${ }^{6}$ Segundo Barros e Prates (1996), o paternalismo se refere a um processo de dependência contínua a que se submetem os liderados por meio de ações desenvolvidas pelos líderes, em uma aceitação mútua.

\section{REFERÊNCIAS BibLIOGRÁfICAS}

Aktouf, O. (1994).

O simbolismo e a cultura de empresa: dos abusos conceituais às lições empíricas. In J. F. Chanlat (Org.). $O$ indivíduo nas organizações: dimensões esquecidas (Vol. 2, pp. 3979). São Paulo: Atlas.

Bardin, L. (1977). Análise de conteúdo. Lisboa: Edições 70.

Barros, B. T., \&

Prates, M. A. (1996).

$O$ estilo brasileiro de administrar. São Paulo: Atlas.

Bogdan, R. C., \&

Biklen, S. K. (1994).

Investigação qualitativa em educação: uma introdução à teoria e aos métodos. Porto Codex: Porto.
Carrieri, A. P. de, \&

Luz, T. R. da (1998, setembro).

Paradigmas e metodologias: não existe pecado do lado de baixo do equador. Anais do Encontro Nacional da Associação Nacional de PósGraduação e Pesquisa em Administração, Foz do Iguaçu, PR, Brasil, 22.

Chanlat, J. F. (1996).

Por uma antropologia da condição humana nas organizações. In J. F. Chanlat (Org.). O indivíduo nas organizações: dimensões esquecidas (Vol. 1, pp. 21-45). São Paulo: Atlas.

Chanlat, J. F. (1999).

Ciências sociais e management. São Paulo: Atlas. 
Chanlat, J. F. (2001).

Prefácio. In E. Davel \& S. C. Vergara (Orgs.). Gestão com pessoas e subjetividade. São Paulo: Atlas.

Davel, E., \&

Vergara, S. C. (2001).

Gestão com pessoas e subjetividade.

São Paulo: Atlas.

Deal, T. E., \&

Kennedy, A. A. (1982).

Corporate cultures: the rites and rituals of corporate life. Reading, Massachusetts: Addison-Wesley.

Dupuis, J. (1996).

Antropologia, cultura e organização: proposta de um modelo construtivista. In J. F. Chanlat (Org.). $O$ indivíduo nas organizações: dimensões esquecidas (Vol. 3, pp. 231251). São Paulo: Atlas.

Giddens, A. (1979).

Central problems in social theory. Berkeley: University of California Press.

Giddens, A. (1984).

The constitution of society. Berkeley: University of California Press.

Martin, J. (1992).

Cultures in organizations: three perspectives. New York: Oxford University Press.

Minayo, M. C. S. (Org.). (2001).

Pesquisa social: teoria, método e criatividade (18a ed.). Petrópolis: Vozes.
Ouchi, W. (1986).

Teoria z: como as empresas podem enfrentar o desafio japonês (10a ed.). São Paulo: Nobel.

Pascale, R. T., \&

Athos, A. G. (1986).

The art of japanese management. London: Penguin Books.

Peters, T. J., \&

Waterman, R. H., Jr. (1986).

Vencendo a crise: como o bom senso empresarial pode superá-la (12a ed.). São Paulo: Harbra.

Poirier, J.,

Clapier-Valladon, S., \&

Raubaut, P. (1983).

Les récits de vie: théorie et pratique. Paris: Puf.

Reed, M. (1985).

Redirections in organizational analysis. London: Tavistock Publications.

Reed, M. (1989).

The sociology of management. London: Harvester Wheatsheaf.

Reed, M. (1995).

The labour process perspective on management organization: a critique and reformulation. In J. Hassard \& D. Pym (Eds.). The theory and philosophy of organizations: critical issues and new perspectives. London: Routledge.

Schein, E. (1985).

Organization cultures and leadership: a dynamic view. San Francisco: Jossey-Bass. 
Triviños, A. N. S. (1987).

Introdução à pesquisa em ciências sociais: a pesquisa qualitativa em educação. São Paulo: Atlas.

Yin, R. K. (2001).

Estudo de caso: planejamento e métodos (2a ed.). Porto Alegre: Bookman.
Zarifian, P. (2001).

Comunicação e subjetividade nas organizações. In E. Davel \& S. C. Vergara (Orgs.). Gestão com pessoas e subjetividade. (pp. 151-170). São Paulo: Atlas. 